BMJ Open

Diabetes

Research

$\&$ Care

\title{
Real-world weight change, adherence, and discontinuation among patients with type 2 diabetes initiating glucagon- like peptide- 1 receptor agonists in the UK
}

\author{
Tracey Weiss (D) , ${ }^{1}$ Lingfeng Yang, ${ }^{1}$ Richard D Carr, ${ }^{1,2}$ Sampriti Pal, ${ }^{3}$ \\ Baanie Sawhney, ${ }^{3}$ Robert Boggs, ${ }^{1}$ Swapnil Rajpathak (D) , ${ }^{1}$ Kristy Iglay ${ }^{1}$
}

To cite: Weiss T, Yang L, Carr RD, et al. Real-world weight change, adherence, and discontinuation among patients with type 2 diabetes initiating glucagon-like peptide-1 receptor agonists in the UK. BMJ Open Diab Res Care 2022;10:e002517. doi:10.1136/

bmjdrc-2021-002517

- Additional supplemental material is published online only. To view, please visit the journal online (http://dx.doi. org/10.1136/bmjdrc-2021002517).

Received 3 August 2021 Accepted 4 January 2022

Check for updates

(C) Author(s) (or their employer(s)) 2022. Re-use permitted under CC BY-NC. No commercial re-use. See rights and permissions. Published by BMJ.

${ }^{1}$ Merck \& Co., Inc, Kenilworth, New Jersey, USA

${ }^{2}$ University College London, London, UK

${ }^{3}$ Complete HEOR Solutions, North Wales, Pennsylvania, USA

Correspondence to Dr Tracey Weiss; tracey.weiss@merck.com

\section{ABSTRACT}

Introduction Glucagon-like peptide-1 receptor agonists (GLP-1 RAs) are a type 2 diabetes mellitus (T2DM) treatment with demonstrated weight loss benefits in clinical trials. However, the extent to which real-world patients with T2DM achieve clinically meaningful weight loss ( $\geq 5 \%$ ) has not been well characterized. Analysis of real-world data suggests adherence to injectable GLP-1 RAs is suboptimal and discontinuation following the first year of therapy is poorly characterized.

Research design and methods A retrospective cohort study among patients with T2DM initiating injectable GLP1 RA therapy was conducted using the Clinical Practice Research Datalink that includes primary care medical records for 13 million patients in the UK. This study assessed weight change, adherence (proportion of days covered (PDC) $\geq 80 \%$ ), and discontinuation ( $\geq 90$-day gap between prescriptions) at 12 and 24 months during the study period spanning January 2009-December 2017. Results Among 589 patients initiating a GLP-1 RA, 56.4\% were female and the median age was 54 years (IQR (46, 61)). The median body mass index was $41.2 \mathrm{~kg} / \mathrm{m}^{2}$ (IQR $(35.8,46.4))$. Among patients with weight measures available ( $\mathrm{n}=341$ at 12 months; $\mathrm{n}=232$ at 24 months), $33.4 \%$ and $43.5 \%$ achieved weight loss $\geq 5 \%$ of baseline weight at 12 and 24 months, respectively. At 12 and 24 months, $64.5 \%$ and $59.2 \%$ were adherent, and $45.2 \%$ and $64.7 \%$ discontinued, respectively.

Conclusions A minority of patients initiating GLP-1 RAs achieved $\geq 5 \%$ weight loss, suggesting the real-world benefit of these agents on weight loss may be lower than that observed in clinical trials. Patients on GLP-1 RAs may benefit from additional support to improve long-term adherence.

\section{INTRODUCTION}

In the UK, the prevalence of type 2 diabetes mellitus (T2DM) doubled from 2.39/1000 person-years in 2000 to $5.32 / 1000$ personyears in 2013. ${ }^{1}$ Cardiovascular disease (CVD) and obesity co-occur frequently among patients with T2DM. A national estimate from 2018 indicated that $35 \%$ of patients

\section{Significance of this study}

What is already known about this subject?

- Glucagon-like peptide-1 receptor agonists (GLP-1 RAs) have demonstrated weight loss in clinical trial participants, although weight loss is poorly characterized among patients with type 2 diabetes (T2DM) in the real world.

- Adherence and discontinuation of GLP-1 RAs after 1 year is also poorly characterized.

What are the new findings?

- Among patients with weight measures available $33.4 \%$ and $43.5 \%$ achieved clinically meaningful weight loss $\geq 5 \%$ of baseline weight at 12 and 24 months, respectively.

- At 24 months, $59.2 \%$ and $64.7 \%$ of patients with T2DM were adherent to or discontinued GLP-1 RA therapy, respectively.

- Median time to discontinuation of GLP-1 RA therapy was 426 days.

How might these results change the focus of research or clinical practice?

- This study suggests real-world weight loss benefit of these drugs may be lower than observed in clinical trials and a substantial portion of patients with T2DM on GLP-1 RAs do not adhere to or discontinue therapy within 2 years.

- Patients may benefit from additional support to improve more long-term adherence to GLP-1 RAs.

with T2DM had CVD. ${ }^{2}$ T2DM, obesity, and CVD increase the likelihood of other comorbidities, including hypertension, chronic kidney disease, metabolic disorders, and liver disease. $^{3}$

Current guidelines from the American Diabetes Association recommend a glucagonlike peptide-1 receptor agonists (GLP-1 RA) or sodium-glucose cotransporter-2 inhibitor as second-line therapy following metformin 
for patients with T2DM with elevated risk of or current CVD, regardless of baseline hemoglobin A1c (HbAlc), or a clinical need to minimize weight gain or promote weight loss. ${ }^{4}$ The National Institute for Health and Care Excellence (NICE) in the UK recommends GLP-1 RAs for individuals with T2DM if triple therapy with metformin and two other oral drugs in ineffective, not tolerated or contraindicated and they have a body mass index $(\mathrm{BMI}) \geq 35 \mathrm{~kg} / \mathrm{m}^{2}$ or, if they have a lower BMI, in whom weight loss would benefit other significant comorbidities; NICE recommends GLP-1 RAs only be continued after 6 months among those who demonstrate a reduction of $11 \mathrm{mmol} / \mathrm{mol}$ or greater in HbA1c and weight loss of $3 \%$ or greater of initial body weight. ${ }^{5}$ These recommendations stem from the demonstrated weight loss and cardiovascular benefits in clinical trials. ${ }^{4}$ Notably, the LEADER (Liraglutide Effect and Action in Diabetes: Evaluation of Cardiovascular Outcome Results) clinical trial enrolled patients with T2DM with history of, or who were at high risk of, CVD and followed them for a median of 3.8 years; patients on liraglutide lost $2.3 \mathrm{~kg}$ more and were less likely (HR $0.87,95 \%$ CI $(0.78$ to 0.97$)$ ) to experience cardiovascular events (13\%) than patients receiving a placebo and standard of care $(14.9 \%){ }^{6}$

Efficacy of medications observed in clinical trials, however, often exceeds the real-world effectiveness, due in part to patients' lower adherence and discontinuation of therapy, as well as the lack of representativeness among clinical trial participants. ${ }^{7}$ Participants in clinical trials tend to be more motivated and have resources and support to comply with the treatment regimens under investigation. ${ }^{8}$

Although randomized trials of GLP-1 RA have demonstrated clinically meaningful weight loss, weight change has not been widely characterized using real-world data among patients naive to GLP-1 RA therapy. ${ }^{9}{ }^{10}$ Real-world data on adherence and persistence tends to focus on the initial limited time frames of 6-12 months of therapy. Furthermore, GLP-1 RAs are known to cause gastrointestinal disturbances, and while these effects may subside after initial use, they have been shown to negatively impact adherence and persistence. ${ }^{11} 12$ Conversely, an analysis of real-world data in the USA showed that modest weight loss after initiating GLP-1 RAs may increase patient adherence. $^{10}$

This retrospective cohort study analyzed patients with T2DM newly prescribed GLP-1 RAs in the UK to characterize weight change and evaluate adherence and discontinuation after 12 and 24 months of follow-up. Differences in the distributions of weight change, adherence and discontinuation by gender, age, baseline BMI, and dosing frequency were also examined.

\section{METHODS}

Study design

Data were extracted from the Clinical Practice Research Datalink (CPRD) database ${ }^{13}$ managed by the UK's
Department of Health. The CPRD database is a longitudinal database of de-identified patient data from a network of general practitioner practices across the UK. It includes 13 million registered patients with data that include demographics, disease diagnoses, clinical data, laboratory tests, and prescriptions. CPRD is validated and recognized as representative of general physician clinical care and the UK general population. ${ }^{13}$

The study period spans from January 1, 2009 until December 31, 2017. The index date was defined as the first prescription for an injectable GLP-1 RA as monotherapy or dual-therapy with metformin following an observed 12-month baseline period (online supplemental figure 1).

\section{Selection and description of participants}

Included patients were at least 18 years of age and diagnosed with T2DM during the baseline period based on Read/Med codes used in the CPRD database (online supplemental table 1). Patients were required to have continuous medical records for the 12-month baseline period and for at least 12 months following the index date. Patients were excluded if they: (1) were diagnosed with other forms of diabetes including type 1, gestational, or other secondary diabetes, (2) were pregnant at any time during the study period or, (3) had prescriptions for antihyperglycemic agents (AHAs) other than metformin during the previous 90 days or 30 days following the first GLP-1 RA prescription (in order to minimize the noise of polypharmacy on assessment of weight change, adherence, and discontinuation). Weight was assessed among those with weight measures available. Adherence was assessed among patients with at least two GLP-1 RA prescription fills (online supplemental figure 2).

\section{Technical information}

\section{Weight change}

Clinically meaningful weight loss was defined as weight loss $\geq 5 \%$ of the patient's baseline weight. ${ }^{14}$ The patients' baseline weight was the baseline period measure prior to and closest to the index date. Weights within a 90-day window of the 12-month and 24-month follow-up dates served as end points. If multiple weight measures were available, the weight closest to the relevant follow-up date was used. Patients were classified into the following BMI categories: $\mathrm{BMI}<30 \mathrm{~kg} / \mathrm{m}^{2} ; 30-34.9 \mathrm{~kg} / \mathrm{m}^{2} ; 35-39.9 \mathrm{~kg} /$ $\mathrm{m}^{2} ; 40-44.9 \mathrm{~kg} / \mathrm{m}^{2}$; and $\mathrm{BMI} \geq 45 \mathrm{~kg} / \mathrm{m}^{2}$.

\section{Adherence}

The proportion of days covered (PDC) methodology served as the assessment for adherence. ${ }^{15}$ PDC was defined as the number of days covered by a GLP-1 RA prescription divided by the number of days during the measurement period. If days of supply were not available, a 30-day supply was assumed. The measurement periods were defined as the time from the index date until the end of 12 months and 24 months, discontinuation of GLP-1 RA medication, or database exit, whichever came first. 
Patients were classified as adherent if the PDC was $\geq 0.80$ at these time points. Adherence was only measured in patients with two or more GLP-1 RA prescription fills.

\section{Discontinuation}

Discontinuation of therapy was defined as having at least a 90-day gap between the last date of a supply of a GLP-1 RA and the first date of subsequent prescriptions (if any). Switching drug brands of GLP-1 RA did not constitute discontinuation unless $>90$ days elapsed between prescriptions. Patients who exited the database were censored and not assumed to have discontinued therapy. If days of supply were not available in the database, a 30-day supply was assumed. A sensitivity analysis defining discontinuation as a treatment gap $>120$ days was performed.

\section{Patient characteristics}

Age, gender, relevant comorbidities, including macrovascular and microvascular complications, laboratory results, BMI, and prescribed GLP-1 RA dosing frequency (weekly, daily) are listed in table 1. Comorbidities were identified during the 12 months prior to the index date and determined from Read codes present in the database or clinical data documented in the record. If a code was not present, patients were classified with hypertension if the medical record included a measure of systolic blood pressure $\geq 140 \mathrm{~mm} \mathrm{Hg}$ or diastolic blood pressure $\geq 90 \mathrm{~mm}$ Hg. Chronic kidney disease was defined based on Read code or having an assessment of estimated glomerular filtration rate $<60 \mathrm{~mL} / \mathrm{min} / 1.73 \mathrm{~m}^{2}$. Hyperlipidemia was defined based on Read code or as a low-density lipoprotein cholesterol $\geq 160 \mathrm{mg} / \mathrm{dL}$.

\section{Statistics}

Frequency distributions were generated for categorical data while means, SD, medians, and quartiles (25th and 75th percentile) were generated for continuous variables. For weight change, results are reported as the mean amount of weight (kg) lost for the cohort with available data and proportion of patients achieving clinically meaningful weight loss $(\geq 5 \%)$ at 12 and 24 months.

Frequencies of adherence and discontinuation by age, gender, and prescription dosing frequency (weekly vs daily), and baseline BMI were generated for each follow-up time point. To investigate patient characteristics associated with GLP-1 RA adherence and discontinuation, bivariate (unadjusted) and multivariable (adjusted) logistic regression models were generated at 12 and 24 months (cumulative). Because baseline BMI was missing for $10.5 \%$ of the cohort, the bivariate models for BMI and the multivariable models that include BMI excluded these patients. Survival analysis was used to produce a Kaplan-Meier (KM) curve of time until discontinuation over 2 years of follow-up.

\section{RESULTS}

A total of 589 patients met the inclusion criteria. Weight measures were available for $57.9 \%$ patients at 12 months and $39.4 \%$ patients at 24 months; $90 \%$ had at least two GLP-1 RA prescriptions to assess adherence.

\section{Patient baseline characteristics}

Mean age was 53.0 years and $56.4 \%$ of the cohort was female (table 1). The mean BMI was $41.7 \mathrm{~kg} / \mathrm{m}^{2}$ indicating a highly obese cohort. Prevalence of CVD was 28.4\%. Mean baseline HbAlc was $49.4 \mathrm{mmol} / \mathrm{mol}$ (SD 36.1) (note: $49 \mathrm{mmol} / \mathrm{mol} \approx 6.6 \%$ ); $78.9 \%$ of patients initiated a daily dose of GLP-1 RA while $21.1 \%$ initiated a weekly dose of GLP-1 RA.

\section{Weight change}

Among patients who had weight measured at 12 months, $33.4 \%$ of patients lost $\geq 5 \%$ of their baseline weight, $37.5 \%$ lost $<5 \%$ and $29.0 \%$ gained weight. Comparatively, at 24 months, $43.5 \%$ of patients with weight measures available lost $\geq 5 \%$ of their baseline weight, while $24.1 \%$ lost $<5 \%$ and $32.3 \%$ gained weight (table 2). Among patients with weight measures available at 12 and 24 months, the mean/median weight change was $-4.6 \mathrm{~kg}$ $(\mathrm{SD} 9.0) /-3.1 \mathrm{~kg}(\mathrm{IQR}-8.0,1.0)$ and $-5.2 \mathrm{~kg}(\mathrm{SD} 11.7) /-$ 4.2 (IQR $-10.0,3.0)$, respectively (table 2 ).

\section{Adherence}

Overall, $64.5 \%$ of patients were adherent to GLP-1 RA therapy at 12 months; adherence decreased to $59.2 \%$ at the cumulative 24-month follow-up (figure 1).

The proportions of patients adherent at 12 and 24 months were comparable by gender; $66.3 \% / 59.7 \%$ of females and $62.2 \% / 58.7 \%$ of males were adherent at $12 / 24$ months. Although a higher proportion of patients $<45$ years of age were adherent compared with the older age groups at both follow-up time points (figure 1), the bivariate and multivariable model showed that the odds of adherence did not differ among age groups (table 3). The proportions of patients adherent to GLP-1 RAs were comparable across most BMI categories as well, ranging between $60.0 \%$ and $68.5 \%$ for all BMI categories except $\mathrm{BMI}<30 \mathrm{~kg} / \mathrm{m}^{2}$ (figure 1). Despite there being an association between having a BMI $<30 \mathrm{~kg} / \mathrm{m}^{2}$ and lower adherence at 12 months (multivariable model OR 0.31 (95\% CI 0.11 to 0.87$)$ ), no association was found between BMI and adherence at 24 months. More patients on a weekly GLP-1 RA were adherent at $12(82.1 \%)$ and $24(74.1 \%)$ months than those on a daily dose $(59.8 \%$ at 12 months, $55.3 \%$ at 24 months). Patients prescribed weekly doses were more likely to adhere to GLP-1 RA therapy than patients prescribed daily doses at both 12 (multivariable model OR 3.09, (95\% CI 1.78 to 5.38) and 24 months (multivariable model OR 2.24 (95\% CI 1.37 to 3.67$)$ ) (table 3 ). The mean PDC was 0.835 at 12 months which decreased to 0.807 at 24 months.

\section{Discontinuation}

The overall proportion of patients who discontinued GLP-1 RA therapy was $45.2 \%$ at 12 months and $64.7 \%$ at 24 months (figure 1). At 12/24 months, 42.8\%/63.3\% and $48.2 \% / 66.5 \%$ of females and males discontinued, 
Table 1 Baseline characteristics of individuals with T2DM from the Clinical Practice Research Datalink initiating GLP-1 RAs $\left(n=589^{\star}\right)$, UK

\begin{tabular}{|c|c|c|c|}
\hline & & $\mathbf{N}(\%)$ & \\
\hline Total & & $589^{*}(100)$ & \\
\hline \multicolumn{4}{|l|}{ Age (years) } \\
\hline$<45$ & & $127(21.6)$ & \\
\hline $45-54$ & & $192(32.6)$ & \\
\hline $55-64$ & & $168(28.5)$ & \\
\hline $65-74$ & & $88(14.9)$ & \\
\hline $75+$ & & $14(2.4)$ & \\
\hline Median (Q1, Q3) & & $54(46,61)$ & \\
\hline Mean (SD) & & $53(11.5)$ & \\
\hline \multicolumn{4}{|l|}{ Gender } \\
\hline Female & & $332(56.4)$ & \\
\hline Male & & $257(43.6)$ & \\
\hline \multicolumn{4}{|l|}{ Dose frequency } \\
\hline Daily† & & $465(78.9)$ & \\
\hline Weekly $\ddagger$ & & $124(21.1)$ & \\
\hline \multicolumn{4}{|l|}{ Comorbidities } \\
\hline \multicolumn{4}{|l|}{ Microvascular complications } \\
\hline Retinopathy & & $55(9.3)$ & \\
\hline Neuropathy & & $25(4.2)$ & \\
\hline Nephropathy & & $10(1.7)$ & \\
\hline \multicolumn{4}{|l|}{ Macrovascular complications } \\
\hline Cardiovascular disease & & $167(28.4)$ & \\
\hline Chronic kidney disease & & $49(8.3)$ & \\
\hline Congestive heart failure & & $15(2.5)$ & \\
\hline \multicolumn{4}{|l|}{ Other diseases } \\
\hline Arrhythmia & & $35(5.9)$ & \\
\hline Depression & & $281(47.7)$ & \\
\hline Angina & & $34(5.8)$ & \\
\hline Hyperlipidemia & & $154(26.1)$ & \\
\hline Malignant neoplasms & & $39(6.6)$ & \\
\hline Hypoglycemia & & $4(0.7)$ & \\
\hline Hypertension & & $401(68.1)$ & \\
\hline \multicolumn{4}{|l|}{ Body mass index $\left(\mathrm{kg} / \mathrm{m}^{2}\right), \mathrm{n}=527$} \\
\hline$<30$ & & $23(3.9)$ & \\
\hline $30-34.9$ & & $84(14.3)$ & \\
\hline $35-39.9$ & & $125(21.2)$ & \\
\hline $40-44.9$ & & $141(23.9)$ & \\
\hline$\geq 45$ & & $154(26.1)$ & \\
\hline Missing & & $62(10.5)$ & \\
\hline Mean (SD) & & $41.7(8.2)$ & \\
\hline Median $(q 1, q 3)$ & & $41.2(35.8,46.4)$ & \\
\hline Laboratory assessments & $\mathrm{N}(\%)$ & Mean (SD) & Median (Q1, Q3) \\
\hline $\mathrm{HbA} 1 \mathrm{c}(\mathrm{mmol} / \mathrm{mol}), \mathrm{n}=576$ & $576(97.8)$ & $49.4(36.1)$ & $57.0(9.1,77.0)$ \\
\hline eGFR (mL/min), $\mathrm{n}=168$ & $168(28.5)$ & 74.5 (14.7) & $77.5(64.0,86.0)$ \\
\hline
\end{tabular}

Continued 
Table 1 Continued

\begin{tabular}{llll}
\hline Laboratory assessments & $\mathbf{N}(\%)$ & Mean (SD) & Median (Q1, Q3) \\
\hline Triglycerides $(\mathrm{mg} / \mathrm{dL}), \mathrm{n}=451$ & $451(76.6)$ & $221.8(155.6)$ & $177.1(132.9,260.4)$ \\
LDL-C (mg/dL), $\mathrm{n}=399$ & $399(67.7)$ & $97.9(39.2)$ & $88.9(69.6,123.7)$ \\
HDL-C (mg/dL), $\mathrm{n}=509$ & $509(86.4)$ & $43.0(10.9)$ & $42.5(34.8,48.7)$ \\
Total cholesterol (mg/dL), $\mathrm{n}=552$ & $552(93.7)$ & $179.7(46.0)$ & $174.0(146.9,208.8)$ \\
SBP $(\mathrm{mm} \mathrm{Hg}), \mathrm{n}=456$ & $456(77.4)$ & $132.5(15.2)$ & $130.0(121.0,140.0)$ \\
DBP $(\mathrm{mm} \mathrm{Hg}), \mathrm{n}=456$ & $456(77.4)$ & $80.8(9.3)$ & $80.0(76.0,85.5)$ \\
\hline
\end{tabular}

${ }^{*} \mathrm{n}=589$ unless otherwise specified in the table.

†Of those on a daily regimen, $46.0 \%$ were initiated on exenatide, $35.3 \%$ on liraglutide, and $18.7 \%$ on lixisenatide.

$\ddagger$ Of those on a weekly regimen, $81.5 \%$ were initiated on exenatide and $18.5 \%$ were on dulaglutide.

DBP, diastolic blood pressure; eGFR, estimated glomerular filtration rate; GLP-1 RA, glucagon-like peptide-1 receptor agonist; HbA1c,

hemoglobin A1c; HDL-C, high-density lipoprotein cholesterol; LDL-C, low-density lipoprotein cholesterol; SBP, systolic blood pressure;

T2DM, type 2 diabetes mellitus.

respectively. At 12 and 24 months, discontinuation rates did not vary greatly between age groups, ranging from $40.9 \%$ to $48.4 \%$ at 12 months and from $60.6 \%$ to $70.7 \%$ at 24 months (figure 1). Moreover, the odds of discontinuation did not differ across gender or age groups in either the bivariate or multivariable model at 12 or 24 months (table 3 ). $54.8 \%$ of patients on weekly doses vs $42.6 \%$ of patients on daily doses discontinued GLP-1 RA therapy within 12 months; these proportions grew to $76.6 \%$ of those on weekly and $61.5 \%$ of those on daily doses discontinued at 24 months. The bivariate and multivariable models show that patients prescribed weekly doses were 1.6-2.1 times as likely to discontinue as patients on daily doses at 12 and 24 months, respectively (table 3). Discontinuation rates increased in each BMI group between 12 and 24 months, but outside of an increased odds of discontinuation for patients with a BMI of $30-34 \mathrm{~kg} / \mathrm{m}^{2}$ at 12 months (multivariable model OR
1.8 (95\% CI 1.05 to 3.19)), no association between BMI group and odds of discontinuation at 12 or 24 months was found.

A Kaplan-Meier plot (figure 2) shows that patients discontinued GLP-1 RA at a median of 426 days $(95 \%$ CI 384 to 476 days) after initiating therapy.

\section{DISCUSSION}

This study described weight change, adherence, and discontinuation patterns of GLP-1 RAs among patients with T2DM newly initiating injectable GLP-1 RA therapy in the UK; $33.4 \%$ and $43.5 \%$ of patients with weight assessments at 12 and 24 months of follow-up lost $\geq 5 \%$ of their baseline weight, respectively. While $59.2 \%$ of patients who remained on therapy were adherent to GLP-1 RA therapy at 24 months, $64.7 \%$ of patients discontinued therapy within that time. Patients with a BMI between 30

Table 2 Weight change at 12 and 24 months follow-up among patients with T2DM initiating GLP-1 RA therapy in the CPRD dataset

\begin{tabular}{|c|c|c|c|c|c|c|}
\hline & \multicolumn{3}{|l|}{ 12-month follow-up } & \multicolumn{3}{|l|}{ 24-month follow-up } \\
\hline & \multicolumn{3}{|l|}{$\mathrm{N}=341$} & \multicolumn{3}{|l|}{$\mathrm{N}=232$} \\
\hline & \multicolumn{3}{|l|}{ n (\%) } & \multicolumn{3}{|l|}{ n (\%) } \\
\hline $\begin{array}{l}\text { Any weight loss or } \\
\text { maintain baseline weight }\end{array}$ & \multicolumn{3}{|l|}{$242(71.0)$} & \multicolumn{3}{|l|}{$157(67.7)$} \\
\hline Weight loss $\geq 5 \%$ & \multicolumn{3}{|l|}{$114(33.4)$} & \multicolumn{3}{|l|}{$101(43.5)$} \\
\hline Weight loss $<5 \%{ }^{*}$ & \multicolumn{3}{|l|}{$128(37.5)$} & \multicolumn{3}{|l|}{$56(24.1)$} \\
\hline \multirow[t]{3}{*}{ Weight gain } & \multicolumn{3}{|l|}{$99(29.0)$} & \multicolumn{3}{|l|}{$75(32.3)$} \\
\hline & \multicolumn{3}{|l|}{ 12-month follow-up } & \multicolumn{3}{|l|}{ 24-month follow-up } \\
\hline & $\begin{array}{l}\text { Weight loss } \geq 5 \% \text { of } \\
\text { baseline weight }\end{array}$ & $\begin{array}{l}<5 \% \text { weight } \\
\text { loss } †\end{array}$ & Overall & $\begin{array}{l}\text { Weight loss } \geq 5 \% \text { of } \\
\text { baseline weight }\end{array}$ & $\begin{array}{l}<5 \% \text { weight } \\
\text { loss } †\end{array}$ & Overall \\
\hline $\begin{array}{l}\text { Mean (SD) weight change, } \\
\mathrm{kg}\end{array}$ & $-13.7(8.6)$ & $0.04(46)$ & $-4.6(9.0)$ & $-14.9(10.2)$ & $2.3(5.8)$ & $-5.2(11.7)$ \\
\hline $\begin{array}{l}\text { Median (Q1, Q3) weight } \\
\text { change, } \mathrm{kg}\end{array}$ & $-11.1(-17.3,-8.0)$ & $-0.8(-3.1,2.1)$ & $-3.1(-8.0,1.0)$ & $-11.0(-21.0,-8.0)$ & $1.3(-3.0,6.0)$ & $-4.2(-10.0,3.0)$ \\
\hline
\end{tabular}

*Includes maintaining baseline weight.

†This includes all patients who lost $<5 \%$ of their baseline weight, maintained their baseline weight, or gained weight.

CPRD, Clinical Practice Research Datalink; GLP-1 RA, glucagon-like peptide-1 receptor agonist; T2DM, type 2 diabetes mellitus. 


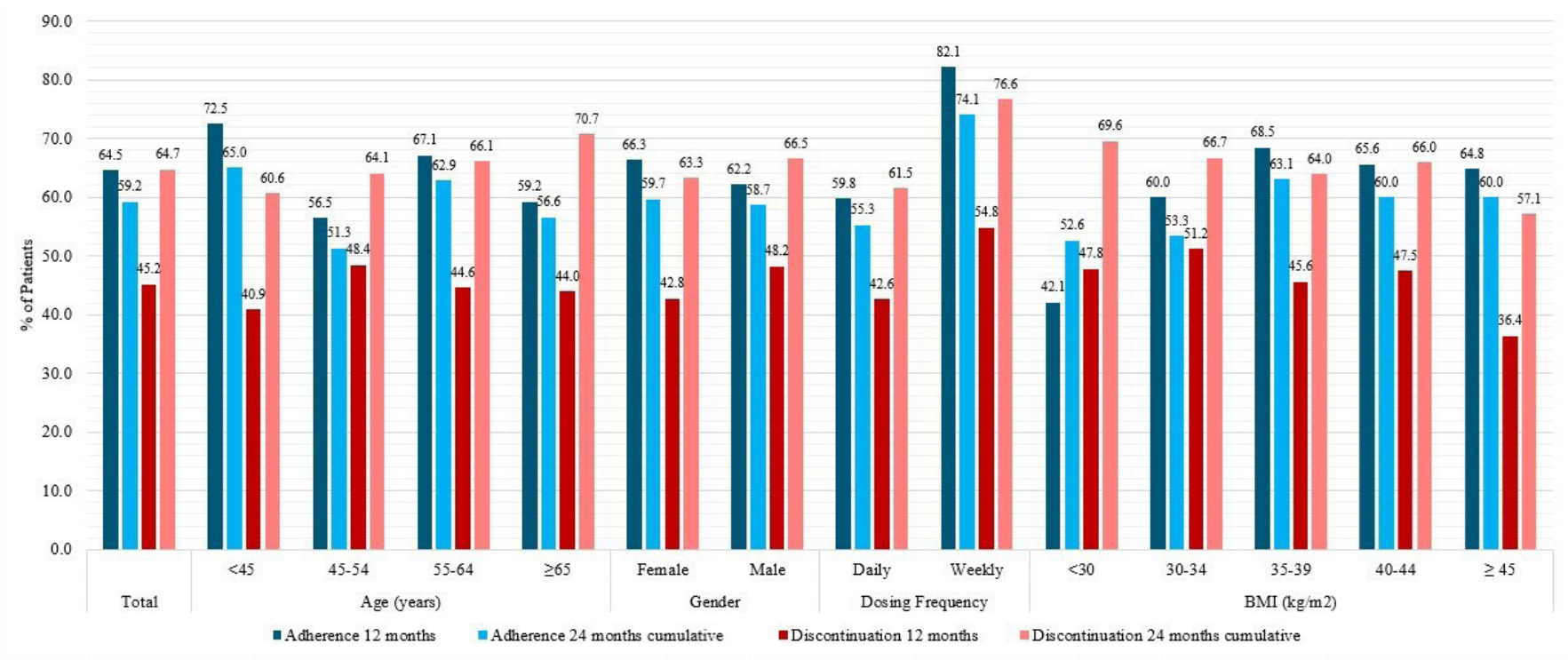

Figure 1 Per cent of patients who were adherent to $(n=530) \dagger$ and discontinued $(n=589)$ GLP-1 RA therapy at 12 and 24 months. †Adherence assessed among patients with two or more GLP-1 RA prescriptions. BMI, body mass index; GLP-1 RA, glucagon-like peptide-1 receptor agonist.

and $34 \mathrm{~kg} / \mathrm{m}^{2}$ were more likely to discontinue therapy at 12 months (bivariate and multivariable model). However, no associations between adherence or discontinuation and BMI were observed at 24 months.

Past GLP-1 RA studies investigating individual GLP-1 RA agents reported weight change as mean kilograms lost and not as a proportion of patients who achieved $\geq 5 \%$ weight loss, have a study population with an comparatively lower BMI, and/or do not extend beyond 1 year. ${ }^{16-20}$ In these studies, mean weight change ranged from $-1.0 \mathrm{~kg}$ to $-3.78 \mathrm{~kg}$ over $6-12$ months. Mean weight change in this study at 12 months was $-4.6 \mathrm{~kg}$. However, $80 \%$ of patients in the present study with available data had a BMI $\geq 35 \mathrm{~kg} / \mathrm{m}^{2}$ and $56 \%$ had BMI $\geq 40 \mathrm{~kg} /$ $\mathrm{m}^{2}$ (median BMI $41.2 \mathrm{~kg} / \mathrm{m}^{2}$ ) compared with mean BMIs in the low to mid 30s in most past studies. Thus, the populations and their weight changes are difficult to compare. Another retrospective analysis using CPRD is an exception; like the present analysis, patients with T2DM given liraglutide had a higher mean weight than those given sitagliptin (mean (SD) $114.3 \mathrm{~kg}$ (22.3) vs 95.4 $\mathrm{kg}$ (20.7), respectively); patients on liraglutide lost 3.78 $\mathrm{kg}$ compared with patients on sitagliptin who lost $1.12 \mathrm{~kg}$ over 6 months. ${ }^{20}$ An analysis of the effects of exenatide over 82 weeks reported that patients taking exenatide in dual therapy with metformin experienced a mean weight loss of $5.3 \mathrm{~kg}$ or $5.2 \%$ of baseline body weight. ${ }^{21}$ Comparatively, the present study found that only $33.4 \%-43.5 \%$ (at 12 and 24 months) of patients lost $\geq 5 \%$ of their baseline weight. This finding suggests that, compared with trials, patients in the real world may not frequently achieve clinically meaningful weight loss. It may also suggest that lifestyle interventions, including diet, physical exercise, and psychological support, remain an important component of a weight management strategy in patients with T2DM as pharmacological therapy alone is unlikely to help the majority of patients achieve clinically meaningful weight loss. Given weight loss is an important criterion for GLP-1 RA therapy persistence per NICE guidelines, ${ }^{5}$ this has important implications for the use of GLP-1 RAs in the UK.

Reported adherence to AHAs is generally highly variable. A meta-analysis of oral AHAs reported the pooled mean medication possession ratio (MPR) to be $75.3 \%$ over 6-24 months of follow-up. ${ }^{22}$ Adherence to GLP-1 RAs specifically has also been shown to vary widely across studies. ${ }^{8}$ Thus, the results of this study are overall consistent with previous reports. ${ }^{82} 24$ The finding that patients on weekly dosing regimens are more adherent than those on daily dosing regimens is also consistent with other studies using administrative and electronic medical records datasets across Europe and the USA. ${ }^{82}$

However, the discontinuation rates in this study were substantially higher than those reported in clinical trials. ${ }^{25}$ The SUSTAIN6 (Trial to Evaluate Cardiovascular and Other Long-term Outcomes With Semaglutide in Subjects With Type 2 Diabetes) trial reported that only $22.6 \%$ of patients prematurely discontinued semaglutide during the 24-month trial period. ${ }^{26}$ Comparatively, this study found that $45.2 \%$ and $64.7 \%$ of patients discontinued by 12 and 24 months, respectively. A sensitivity analysis expanding the allowable gap between end of days of supply of one prescription to start of a new prescription to 120 days did not substantially alter discontinuation rates $(43.1 \%$ at 12 months, $63.3 \%$ at 24 months); this supports the conclusion that a majority of GLP-1 RA new users truly did discontinue therapy in those time periods. The results for discontinuation by dosing schedule (weekly vs daily) diverge from other real-world studies for reasons that are unclear. While other studies 


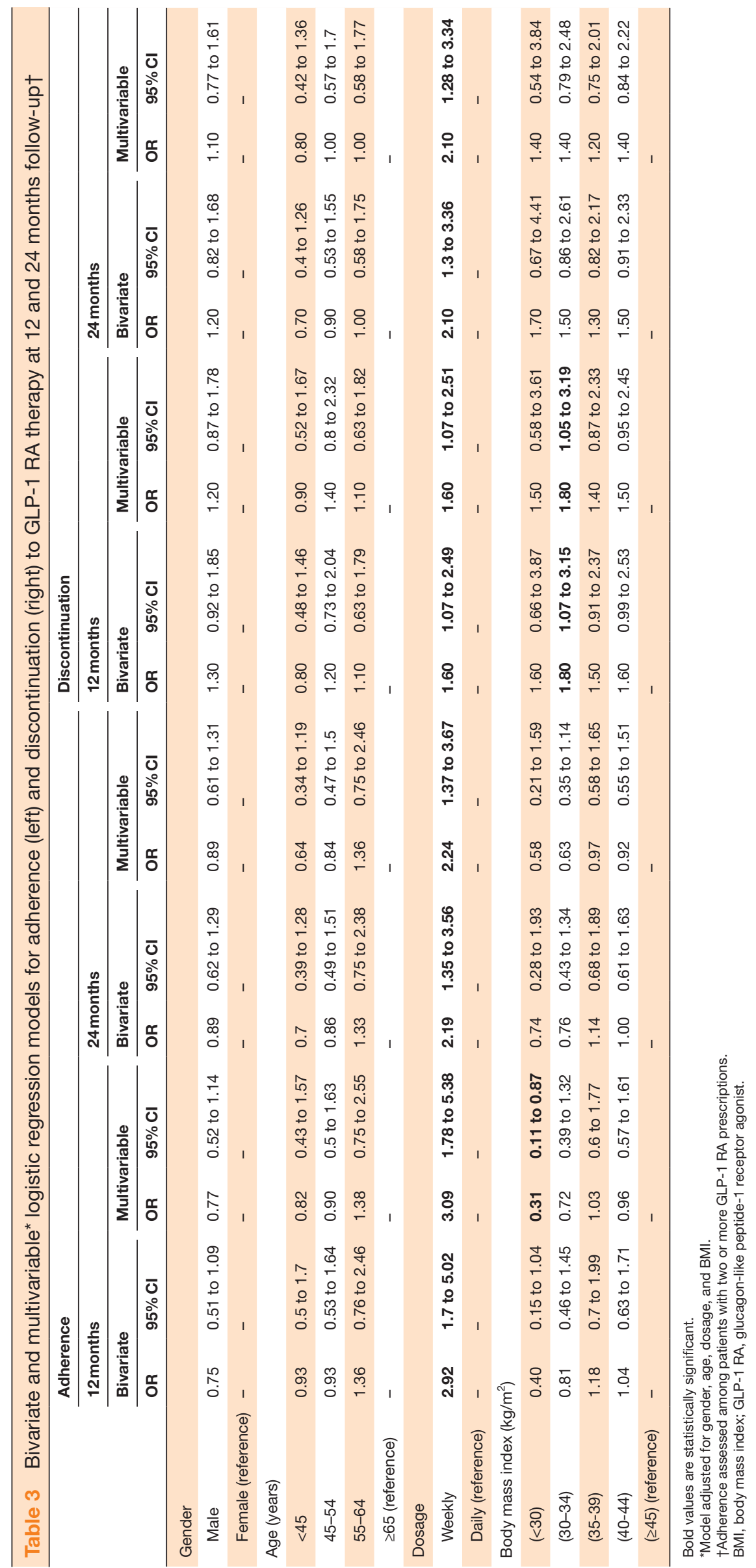




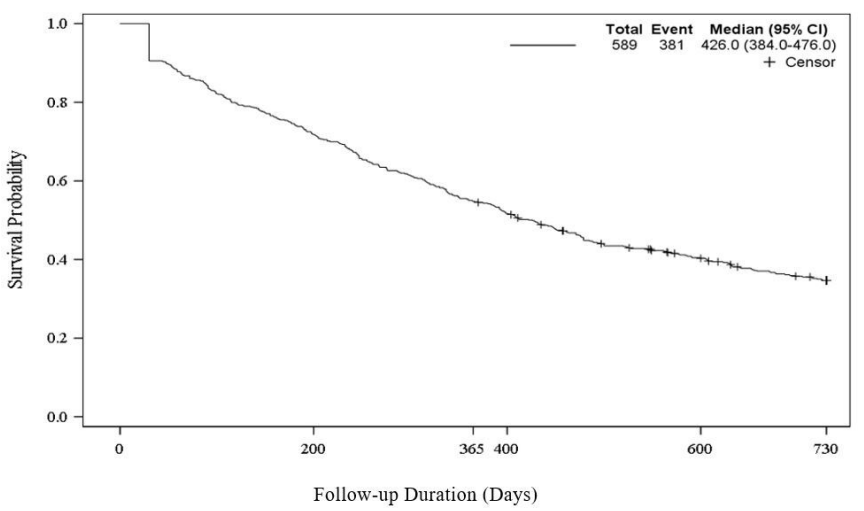

Figure 2 Time to discontinuation of GLP-1 RAs, KaplanMeier plot, $n=589$. Patients discontinued a median of 426 days $(95 \% \mathrm{Cl} 384$ to 474$)$ after initiating GLP-1 RA therapy. GLP-1 RA, glucagon-like peptide-1 receptor agonist.

have reported greater discontinuation among patients prescribed daily doses compared with weekly doses, ${ }^{232527}$ the present study found patients on weekly GLP-1 RAs were significantly more likely to discontinue therapy than those on daily GLP-1 RAs.

The high rates of discontinuation observed in this study prompt consideration of the real-world impact of GLP-1 RA on outcomes. In the LEADER trial, patients at risk for CVD experienced significantly fewer cardiovascular events and deaths than the placebo group after 36 months. ${ }^{6}$ The findings of the present study suggest that outside the context of randomized trials, patients prescribed GLP-1 RAs discontinue therapy sooner which may impact GLP-1 RAs effectiveness in the real world. The few studies that have evaluated real-world effectiveness of GLP-1 RAs have yielded inconsistent results. ${ }^{8} 2028-30$ Future studies should consider evaluating the impact of adherence and persistence on glycemic control, weight, and other outcomes, in totality and by pharmacological agent or class, to better understand potential gaps in translating randomized trials efficacy into real-world effectiveness.

This study has several limitations. The sample sizes were relatively small: 589 patients met the inclusion criteria; 530 patients had at least two GLP-1 RA prescriptions to be included in the adherence analysis. The small study population was, in part, due to limiting the study to patients without evidence of AHAs other than metformin in the 90 days prior and 30 days after GLP-1 RA initiation. While this criterion reduced the impact of polypharmacy on assessments of weight, adherence, and discontinuation, it also reduced the applicability of its findings to the broader T2DM population. Additionally, patient weights over the follow-up period were available for a fraction of the full cohort and may be subject to unknown biases. It is also worth noting that the impact of lifestyle modifications on weight results could not be ascertained. Adherence was measured using data from electronic health records for prescriptions and calculating PDC. Determining whether patients actually took the medication or took the medication as prescribed would require intensive monitoring. That said, this study used the PDC method because of its increased sensitivity to capturing uncovered days compared with MPR, another commonly used method for estimating adherence. ${ }^{15}$ Identification of baseline comorbidities was subject to the presence of Read codes and thus may be under-reported. As with other observational studies, it is possible unaccounted for confounding factors may have influenced the results. It is also worth noting that this study investigated injectable GLP-1 RAs only; its findings may not be applicable to oral GLP-1 RAs. Additionally, the markedly higher rates of obesity in this study's population may reflect a channeling bias; it is possible that physicians' prefer to prescribe GLP-1 RAs to their patients with greater obesity given the medication's demonstrated weight loss benefit in clinical trials. ${ }^{414}$ This may impact the generalizability of this study to a broader T2DM UK population. Finally, this was an observational research study of T2DM in the UK using primary care electronic medical records. Its findings, therefore, may not be applicable to other populations.

In conclusion, one in three patients with body weight measures available achieved clinically meaningful weight loss at 12 months. Although approximately $60 \%$ of the cohort was adherent during their observed time on therapy, nearly half of patients discontinued GLP-1 RA therapy within 12 months and nearly two-thirds discontinued within 24 months. Patients may benefit from additional support to improve more long-term adherence to GLP-1 RAs. Further investigation of the association between adherence and weight change on real-world effectiveness of GLP-1 RAs is warranted.

Acknowledgements The authors would like to thank Irene Doherty, PhD, of Complete HEOR Solutions, for her drafting and editorial assistance of the manuscript and statistical analysis guidance.

Contributors TW, LY, SP, SR, and KI contributed to the concept, design, and planning of the study. TW, LY, SP, BS, RB, and KI contributed to the analysis of the data. All coauthors contributed to the interpretation of the study results. TW contributed to drafting the manuscript alongside medical writer, Irene Doherty. The remaining coauthors contributed to critically reviewing and revising the manuscript. TW is guarantor for this work.

Funding This study was funded by Merck Sharp \& Dohme Corp., a subsidiary of Merck \& Co., Inc., Kenilworth, New Jersey, USA.

Competing interests TW, LY, RB, SR, and KI are/were employees of Merck Sharp \& Dohme Corp., a subsidiary of Merck \& Co., Inc., Kenilworth, New Jersey, USA at the time of study conduct. RDC was an employee of MSD UK, London, UK at the time of study conduct and holds an honorary position at University College, London, UK. BS and SP were external contractors of Complete HEOR Solutions whose analysis services were paid for by Merck \& $\mathrm{Co}$., Inc.

Patient consent for publication Not applicable.

Ethics approval This study did not require IRB approval as it was a retrospective database study in which subjects were properly de-identified to maintain confidentiality. No human subjects were at risk during this study.

Provenance and peer review Not commissioned; externally peer reviewed.

Data availability statement All data relevant to the study are included in the article or uploaded as supplementary information. Merck licensed the data used in this study and does not have permission to release the data or share with any third party without explicit contractual consent. The study protocol contains 
specifications of the database and patient selection. The study protocol is available on request.

Supplemental material This content has been supplied by the author(s). It has not been vetted by BMJ Publishing Group Limited (BMJ) and may not have been peer-reviewed. Any opinions or recommendations discussed are solely those of the author(s) and are not endorsed by BMJ. BMJ disclaims all liability and responsibility arising from any reliance placed on the content. Where the content includes any translated material, BMJ does not warrant the accuracy and reliability of the translations (including but not limited to local regulations, clinical guidelines, terminology, drug names and drug dosages), and is not responsible for any error and/or omissions arising from translation and adaptation or otherwise.

Open access This is an open access article distributed in accordance with the Creative Commons Attribution Non Commercial (CC BY-NC 4.0) license, which permits others to distribute, remix, adapt, build upon this work non-commercially, and license their derivative works on different terms, provided the original work is properly cited, appropriate credit is given, any changes made indicated, and the use is non-commercial. See: http://creativecommons.org/licenses/by-nc/4.0/.

ORCID iDs

Tracey Weiss http://orcid.org/0000-0001-6524-2412

Swapnil Rajpathak http://orcid.org/0000-0002-6052-2949

\section{REFERENCES}

1 Sharma M, Nazareth I, Petersen I. Trends in incidence, prevalence and prescribing in type 2 diabetes mellitus between 2000 and 2013 in primary care: a retrospective cohort study. BMJ Open 2016;6:e010210.

2 Lautsch D, Wang T, Yang L, et al. Prevalence of established cardiovascular disease in patients with type 2 diabetes mellitus in the UK. Diabetes Ther 2019;10:2131-7. doi:10.1007/s13300-01900698-9

3 Iglay K, Hannachi H, Joseph Howie P, et al. Prevalence and coprevalence of comorbidities among patients with type 2 diabetes mellitus. Curr Med Res Opin 2016;32:1243-52. doi:10.1185/0300799 5.2016 .1168291

4 American Diabetes Association. 9. Pharmacologic Approaches to Glycemic Treatment: Standards of Medical Care in Diabetes-2021. Diabetes Care 2021;44:S111-S124-24. doi:10.2337/dc21-S009

5 National Institute for Health and Care Excellence. Type 2 diabetes in adults: management, 2015. Available: https://www.nice.org.uk/ guidance/ng28/resources/type-2-diabetes-in-adults-managementpdf-1837338615493 [Accessed 21 Nov 2021].

6 Marso SP, Daniels GH, Brown-Frandsen K, et al. Liraglutide and cardiovascular outcomes in type 2 diabetes. $N$ Engl J Med Overseas Ed 2016;375:311-22. doi:10.1056/NEJMoa1603827

7 Nordon C, Karcher H, Groenwold RHH, et al. The "EfficacyEffectiveness Gap": Historical Background and Current Conceptualization. Value Health 2016;19:75-81.

8 Guerci B, Charbonnel B, Gourdy P, et al. Efficacy and adherence of glucagon-like peptide-1 receptor agonist treatment in patients with type 2 diabetes mellitus in real-life settings. Diabetes Metab 2019;45:528-35.

9 Trujillo JM, Nuffer W, Ellis SL. Glp-1 receptor agonists: a review of head-to-head clinical studies. Ther Adv Endocrinol Metab 2015;6:19-28.

10 Durden E, Liang M, Fowler R, et al. The effect of early response to GLP-1 RA therapy on long-term adherence and persistence among type 2 diabetes patients in the United States. J Manag Care Spec Pharm 2019;25:669-80.

11 Garber AJ. Long-Acting glucagon-like peptide 1 receptor agonists: a review of their efficacy and tolerability. Diabetes Care 2011;34 Suppl 2:S279-84

12 McGovern A, Tippu Z, Hinton W, et al. Comparison of medication adherence and persistence in type 2 diabetes: a systematic review and meta-analysis. Diabetes Obes Metab 2018;20:1040-3. doi:10.1111/dom.13160

13 Herrett E, Gallagher AM, Bhaskaran K, et al. Data resource profile: clinical practice research Datalink (CPRD). Int J Epidemiol 2015;44:827-36

14 Wing RR, Lang W, Wadden TA, et al. Benefits of modest weight loss in improving cardiovascular risk factors in overweight and obese individuals with type 2 diabetes. Diabetes Care 2011;34:1481-6.

15 Andrade SE, Kahler KH, Frech F, et al. Methods for evaluation of medication adherence and persistence using automated databases. Pharmacoepidemiol Drug Saf 2006;15:565-74. doi:10.1002/ pds. 1230

16 Nauck M, Frid A, Hermansen K, et al. Efficacy and safety comparison of liraglutide, glimepiride, and placebo, all in combination with metformin, in type 2 diabetes. Diabetes Care 2009;32:84-90.

17 Garber A, Henry R, Ratner R, et al. Liraglutide versus glimepiride monotherapy for type 2 diabetes (LEAD-3 mono): a randomised, 52-week, phase III, double-blind, parallel-treatment trial. Lancet 2009;373:473-81.

18 Zinman B, Gerich J, Buse JB, et al. Efficacy and safety of the human glucagon-like peptide-1 analog liraglutide in combination with metformin and thiazolidinedione in patients with type 2 diabetes (LEAD-4 Met+TZD). Diabetes Care 2009;32:1224-30.

19 Umpierrez G, Tofé Povedano S, Pérez Manghi F, et al. Efficacy and safety of dulaglutide monotherapy versus metformin in type 2 diabetes in a randomized controlled trial (AWARD-3). Diabetes Care 2014;37:2168-76.

20 Nyeland ME, Ploug UJ, Richards A, et al. Evaluation of the effectiveness of liraglutide and sitagliptin in type 2 diabetes: a retrospective study in UK primary care. Int $\mathrm{J}$ Clin Pract 2015;69:281-91.

21 Blonde L, Klein EJ, Han J, et al. Interim analysis of the effects of exenatide treatment on $\mathrm{A} 1 \mathrm{c}$, weight and cardiovascular risk factors over 82 weeks in 314 overweight patients with type 2 diabetes. Diabetes Obes Metab 2006;8:436-47.

22 Iglay K, Cartier SE, Rosen VM, et al. Meta-Analysis of studies examining medication adherence, persistence, and discontinuation of oral antihyperglycemic agents in type 2 diabetes. Curr Med Res Opin 2015;31:1283-96. doi:10.1185/03007995.2015.1053048

23 Wilke T, Mueller S, Groth A, et al. Non-Persistence and NonAdherence of patients with type 2 diabetes mellitus in therapy with GLP-1 receptor agonists: a retrospective analysis. Diabetes Ther 2016;7:105-24. doi:10.1007/s13300-015-0149-4

24 Qiao Q, Ouwens MJ, Grandy S, et al. Adherence to GLP-1 receptor agonist therapy administered by once-daily or once-weekly injection in patients with type 2 diabetes in Germany. Diabetes Metab Syndr Obes 2016:9:201-5. doi:10.2147/DMSO.S99732

25 Federici MO, McQuillan J, Biricolti G, et al. Utilization patterns of glucagon-like peptide-1 receptor agonists in patients with type 2 diabetes mellitus in Italy: a retrospective cohort study. Diabetes Ther 2018;9:789-801. doi:10.1007/s13300-018-0396-2

26 Marso SP, Bain SC, Consoli A, et al. Semaglutide and cardiovascular outcomes in patients with type 2 diabetes. N Engl $\mathrm{J} \mathrm{Med}$ 2016;375:1834-44. doi:10.1056/NEJMoa1607141

27 Malmenäs M, Bouchard JR, Langer J. Retrospective real-world adherence in patients with type 2 diabetes initiating once-daily liraglutide $1.8 \mathrm{Mg}$ or twice-daily exenatide $10 \mu \mathrm{g}$. Clin Ther 2013:35:795-807. doi:10.1016/. clinthera.2013.03.021

28 Dhesi B, Chauhan H, Basu A. Audit of clinical practice in the use of incretin mimetic agents for the management of patients with type 2 diabetes. Practical Diabetes 2013;30:159-62.

29 Coleman $\mathrm{Cl}$, Pandya S, Wang L, et al. Treatment patterns, glycemic control and bodyweight with canagliflozin $300 \mathrm{mg}$ versus GLP1RAs in Type II diabetes patients. J Comp Eff Res 2019;8:889-905.

30 Thomsen RW, Baggesen LM, Søgaard M, et al. Early glycaemic control in metformin users receiving their first add-on therapy: a population-based study of 4,734 people with type 2 diabetes. Diabetologia 2015:58:2247-53. doi:10.1007/s00125-015-3698-1 